Article

\title{
Chest pain symptoms differences between diabetes mellitus and non-diabetes mellitus patients with acute coronary syndrome: A pilot study
}

\author{
Halidah Manistamara, ${ }^{1}$ Yurike Olivia Sella, ${ }^{1}$ Sony Apriliawan, ${ }^{1}$ Mifetika Lukitasari,,${ }^{1,2}$ \\ Mohammad Saifur Rohman',3,4
}

${ }^{1}$ School of Nursing, Faculty of Medicine, Universitas Brawijaya, Malang; ${ }^{2}$ Cardiovascular Research Group, Faculty of Medicine, Universitas Brawijaya, Malang; ${ }^{3}$ Department of Cardiology and Vascular Medicine, Faculty of Medicine, Universitas Brawijaya, Malang; ${ }^{4}$ Saiful Anwar General Hospital, Malang, Indonesia

\begin{abstract}
Background: Chest pain is considered one of the crucial indicators in detecting acute coronary syndrome (ACS), and one of the most common complaints frequently found in hospitals. Atypical characteristics of chest pain have prevented patients from being aware of ACS. Chest pain symptoms have become ambiguous, particularly for specific parameters, such as gender, diabetes mellitus (DM), or other clinical conditions. Therefore, it is critical for high-risk patients to have adequate knowledge of specific symptoms of ACS, which is frequently associated with late treatment or prehospital delay. Therefore, this study aims to identify the particular characteristics of chest pain symptoms in DM and non-DM patients with ACS.

Design and Methods: This is a quantitative and non-experimental research, with the cross-sectional approach used to carry out the analytical observation at a general hospital from JanuaryApril 2019. Data were obtained from a total sample of 61 patients, comprising 33 ACS with DM and 28 ACS non-DM patients.

Results: The result showed that the characteristic of patients with chest pain symptoms has a significant relation to DM and ACS. Therefore, non-DM patients with ACS are more likely to feel chest pain at moderate to a severe level, while ACS-DM patients are more likely to have low to moderate chest pain levels.

Conclusion: The significant differences in the characteristics of chest pain in DM and non-DM patients suffering from acute coronary syndrome are the points of location of chest pain radiating to the neck and quality of pain.
\end{abstract}

\section{Introduction}

Cardiovascular disease is the most severe cause of death among all non-infectious diseases and accountable for 17.5 million deaths in the world. This means that $46 \%$ of global deaths are attributed to non-infectious diseases, with approximately 7.4 million caused to ischemic heart disease. ${ }^{1}$ According to data from Jakarta Acute Coronary Syndrome (JACS) registry, a total of 1223, 1915, and 1925 patients suffered from non-ST elevation myocardial infarction (NSTEMI) of the acute coronary syndrome (ACS) in 2007, 2010 and 2013, respectively. ${ }^{2}$ These numbers showed that the prevalence of ACS has experienced increment over the years. Conversely, the ACS Registry in the hospital recorded approximately 1-2 ACS patients per day. Acute coronary syndrome requires early identification and management to prevent further severe complication. ${ }^{3,4}$ Studies have considered chest pain as a critical indicator and main complaint in detecting this disease. ${ }^{5}$ Atypical characteristic of chest pain makes the patient unaware of having ACS due to its ambiguity, especially in specific parameters such as gender differences, diabetes mellitus, or any other clinical conditions. ${ }^{5}$ Therefore, it is critical for high-risk and ACS patients to perceive the specific symptoms correctly since it has been frequently associated with late treatment or prehospital delay, which is one of the leading causes of ACS morbidity and increase in mortality rate. ${ }^{6-8}$

Diabetes mellitus also takes into account the increased mortality rate due to ACS. According to previous studies, ${ }^{6-9}$ ACS patients with diabetes mellitus experience symptomatic conditions, such as atypical chronic and acute ischemia, which is mainly observed in type $2 \mathrm{DM}$ patients. Heart mortality in patients with DM is frequently associated with prevalence silent ischemia, which is triggered by autonomic neuropathy, thereby decreasing the chest pain felt by them. Therefore, it leads to uncertainty of patients in early and appropriate detection of ACS. ${ }^{10,11}$

Several studies have been carried out in studying chest pain characteristics in DM patients. However, such studies are rarely found in Indonesia. Therefore, based on the description above, this study aims to investigate the characteristic of chest pain in ACS patients with DM at a general hospital in Malang, East Java, Indonesia.

There are lots of differences in the various chest pain symptoms experienced by diabetes mellitus and non-diabetes mellitus patients with the acute coronary syndrome. Therefore, this study aims to provide optimal nursing care to patients and educate them along with their family members on the various chest pain symptoms to avoid delay in seeking medical attention. 


\section{Design and Methods}

This is a quantitative non-experimental research, with the analytical observation method used to carry out the cross-sectional study at a general hospital in Malang, East Java, Indonesia from January-April 2019. Furthermore, the respondents were selected through the purposive sampling method. The inclusion criteria used in this study are as follows: i) Patients diagnosed with STEMI and NSTEMI; ii) patients are male; iii) above the age of 40 years; iv) Patients with acute myocardial infarction without chest pain (angina) for 24 hours; v) patients who are hemodynamically stable; vi) patients without acute decompensated heart failure (ADHF); vii) patients without malignant arrhythmias, viii) patients without in Acute Lung Oedem (ALO) condition; ix) patients not using ventilator; x) patient willing to and become respondents. Meanwhile, the exclusion criteria used in this study are: i) Patients with several complications, thereby making it impossible to interview them; ii) patients who have never undergone CABG surgery; iii) patients who refuse to be respondents. Based on the inclusion and exclusion criteria, the total sample obtained in this study is 61 patients.

This study utilized the chi-square statistic test to analyse the demographic characteristics and its differences in chest pain of
DM and non-DM patients with the acute coronary syndrome. The questionnaire used in this study is a modified flowchart (SCORE chart). ${ }^{12}$ Furthermore, the study was approved by the Institutional Ethics Committee of Dr. Saiful Anwar Hospital, number 400/016/K.3/302/2019.

\section{Results and Discussions}

The patient's baseline characteristics observed in this research include ages, body mass index, marital status, educational background, occupation, type of payment, clinical history and medical diagnosis. Table 1 shows the distribution analysis result of baseline characteristics of ACS patients at the hospital. The total number of respondents in this study are 61 patients, consisting of $33 \mathrm{ACS}$ patients with diabetes mellitus and 28 ACS without DM. Table 1 shows that out of the baseline characteristics of patients, only two types of payment and hypertension record where significant to respondents suffering from chest pain $(\mathrm{p}<0.05)$. Therefore, a significant number of ACS patients bearing DM tend to carry out payment using varying JKN general payment and employment insurance strategies. Furthermore, the proportion of hypertension as a

Table 1. Baseline characteristics.

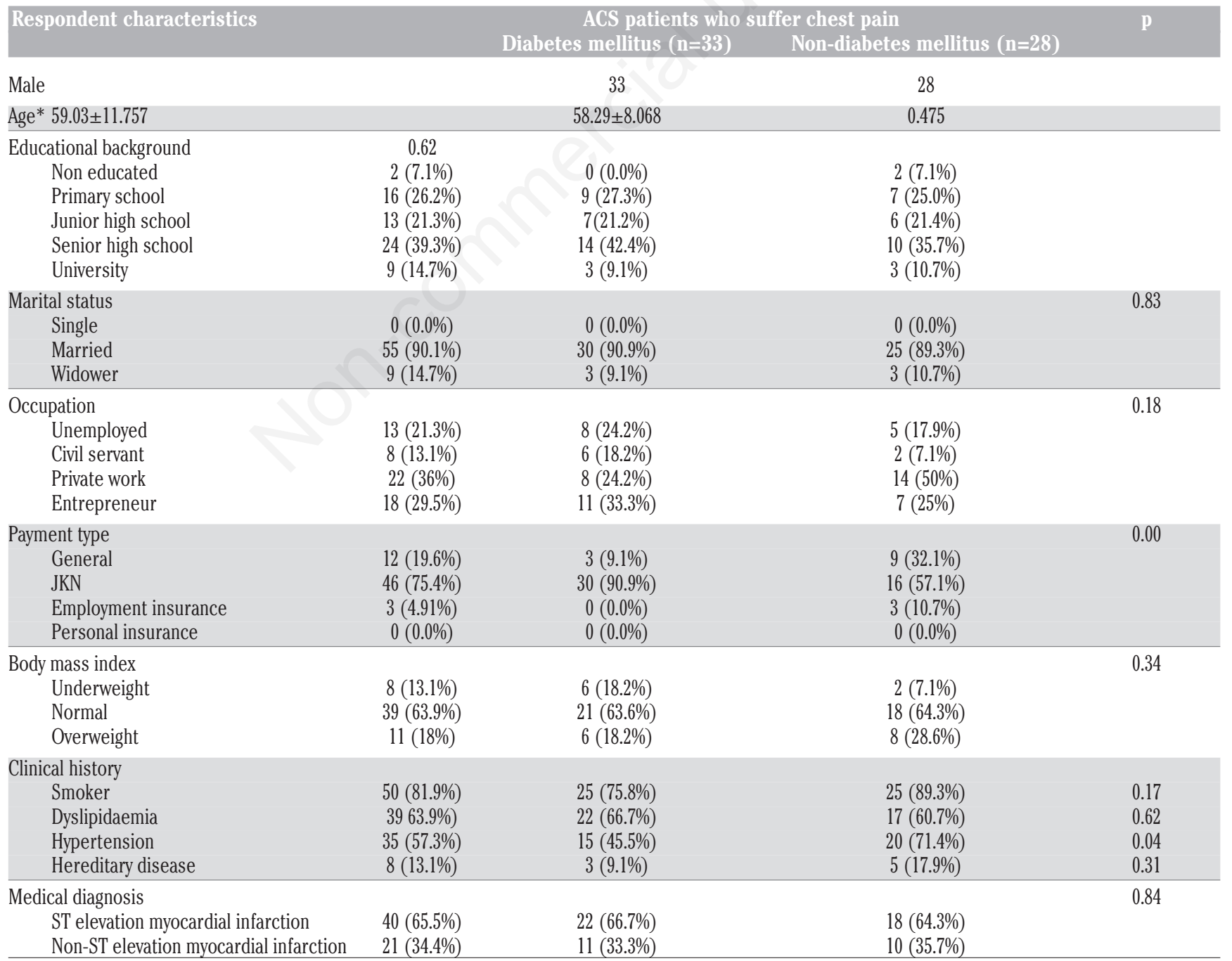


risk factor is also shown to be significantly higher than the ACS group with non-DM.

Table 2, shows the chest pain characteristic differences in ACS patient which distinct DM from non-DM. The results indicate that out of 6 points related to chest pain characteristics, 2 had significant relations $(\mathrm{p}<0.05)$. The table also indicates a point of chest pain location, which attacks around the chest and radiates around the neck. Chest pain proportion in radiating to the neck is relatively higher in ACS patients non-DM than ACS patients with DM. Table 3 shows the analysis result regarding the characteristic of typical symptoms in ACS patients with DM and non-DM. Out of all points mentioned above, the value of $\mathrm{p}$ is over 0.05 which corresponds to the fact that there are no significant differences between atypical symptoms in ACS patients with DM and non-DM, as shown in
Table 2. Therefore, it can be concluded that symptoms are typically not affected by clinical history of diabetes mellitus.

The characteristics of chest pain used in this study consist of 6 points, namely location, triggers, duration, sensations, levels and history. Out of the 6 characteristics, 2 have significant $\mathrm{p}$ values below 0.05 , namely areas around the chest pain location and radiating to the neck, as well as the chest pain level. In the point of chest pain location, between ACS patients with DM and non DM, both have a proportional comparison in a higher number of patients suffering chest pain from left to middle. This is because the anatomical position of the heart is on the left side, therefore the pain tends to radiate more on that side through the cervical nerve. ${ }^{12,13}$ However, significant differences were obtained in chest location that radiates to the neck with a p-value less than 0.05 .

Table 2. Chest pain characteristics.

Chest pain location

Left chest or middle chest

Chest, through to back

Chest, radiated to left hand

Chest, radiated to neck

Chest, radiated to chin

Epigastric

Chest pain trigger

Triggered by regular activities, diminished after resting

Triggered by regular activities, not reduced with resting or ISDN

Triggered by light activities

Triggered by when resting

Chest pain duration

$>20$ mins

$<20$ min

Chest pain sensation

Like getting ripped off or sudden

Burnt or stabbed

Crushed or suppressed

Getting more severe with foods/ position changes/inhaling air

Chest pain level

Low pain

Moderate pain

Severe pain

Chest pain history

Never

Ever, but with lower pain than before

Ever, same as usual

Ever, more severe than before

ACS, acute coronary syndrome; ISDN, slow-release isosorbide dinitrate.

Table 3. Characteristics of atypical symptoms.

\begin{tabular}{|c|c|c|c|}
\hline & & & p \\
\hline & Diabetes mellitus ( $\mathrm{n=33}$ ) & Non-diabetes mellitus ( $\mathrm{n}=\mathbf{2 8}$ ) & \\
\hline Nausea & $18(54.5 \%)$ & $14(50.0 \%)$ & 0.723 \\
\hline Throw up & $11(33.3 \%)$ & $10(35.7 \%)$ & 0.845 \\
\hline Shortness of breath & $19(57.6 \%)$ & $19(67.9 \%)$ & 0.409 \\
\hline Stomach ache & $2(6.1 \%)$ & $1(3.6 \%)$ & 0.654 \\
\hline Cold sweat & $25(75.8 \%)$ & $25(89.3 \%)$ & 0.171 \\
\hline
\end{tabular}

$26(78.8 \%)$

$20(60.6 \%)$

$2(6.1 \%)$

$1(3.0 \%)$

$1(3.0 \%)$

$8(24.2 \%)$

$5(12.5 \%)$

$11(33.3 \%)$

$2(5.1 \%)$

$15(45.5 \%)$

$26(78.8 \%)$

$7(21.2 \%)$

$0(0.0 \%)$

$17(51.5 \%)$

$15(45.5 \%)$

$1(3.0 \%)$

$9(27.3 \%)$

$16(48.5 \%)$

$8(24.2 \%)$

25 (75.8\%)

$2(6.1 \%)$

$3(9.1 \%)$

$3(9.1 \%)$
$25(89.3 \%)$
$17(60.7 \%)$
$6(21.4 \%)$
$6(21.4 \%)$
$1(3.6 \%)$
$6(21.4 \%)$

0.270

0.993

0.076

0.025

0.906

0.795

$5(17.9 \%)$

$11(39.3 \%)$

$2(7.1 \%)$

$10(35.7 \%)$

$24(85.7 \%)$

4 (14.3\%)

$16(57.1 \%)$

$10(35.7 \%)$

$2(7.1 \%)$

0.045

$1(3.6 \%)$

$18(64.3 \%)$

9 (32.1\%)

18 (64.3\%)

$1(3.6 \%)$

$2(7.1 \%)$

7 (25.0\%) 
Chest pain location that radiates to the neck occurs to ACS patients with DM. This fact was supported by a previous study, ${ }^{14}$ which stated that ACS patients with DM or those with high-risk tend to suffer atypical chest pain which is triggered on the side of atypical pain distribution, such as the arm, shoulder, back, etc. This is in line with the researches carried out by DeVon ${ }^{14}$ and Funk, ${ }^{15}$ which stated that area or location of chest pain distribution which frequently occurred in ACS patients with DM is on the arm, neck, chin and back.

Generally, ACS patients with non-DM tends to suffer more atypical chest pain which initiated on the left or middle chest. ${ }^{16}$ However, there are no significant differences in chest pain location between ACS patients with DM and non-DM. This is because, in patients with DM, chest pain seems to be rather biased. Therefore, several numbers of patients are considered difficult to describe the exact location of chest pain. ${ }^{17-19}$ This can be possibly proposed as references in the identification of chest pain characteristics in the future.

Another point with significant differences is chest pain level with a p-value below 0.05 is patients with acute coronary syndrome and DM. This category of patients has low and moderate chest pain level, while those with and non-DM have moderate to severe pains. According to the previous research, ${ }^{13,17}$ ACS patients with DM tend to be incapable of feeling pains, or inconveniences around the chest. This is because there is a mechanism of cardiac autonomic neuropathy which causes damage to autonomic nerve fibres. ${ }^{11}$ Therefore, the delivery of pain stimuli from the myocardium to cerebral is hindered and eventually leads to the inability to identify pain. ${ }^{11,17}$ Therefore, this leads to difficulties in early detection process of acute coronary syndrome symptoms, thereby increasing the mortality rate due to silent ischemia. ${ }^{20-22}$ Furthermore, ACS patients with DM frequently experience asymptomatic indication, such as cold sweat or difficulty in breathing. ${ }^{23,24}$ However, in this research, there are no significant differences in asymptomatic indication of patients with DM or non DM.

\section{Conclusion}

The significant differences in the characteristics of chest pain in patients with acute coronary syndrome with diabetes mellitus and non-diabetes Mellitus are the points of location, which radiates to the neck and the quality of pain. Acute coronary syndrome patients with diabetes mellitus tend to feel chest pain radiating to the neck more than those with acute coronary syndrome and nondiabetes Mellitus. The scale of chest pain at mild to moderate levels is generally more pronounced in patients with the acute coronary syndrome with diabetes mellitus than in those without diabetes mellitus. Furthermore, there were no significant differences in the asymptomatic symptoms felt by the two groups of patients with acute coronary syndrome.
Correspondence: Mifetika Lukitasari, School of Nursing, Faculty of Medicine, Universitas Brawijaya, Jl. Puncak Dieng, Kunci, Kalisongo, Kec. Dau, Malang, East Java Indonesia 65151. Tel: +62341569117 - Fax: +62341564755.

E-mail: mifetika.fk@ub.ac.id

Acknowledgement: The authors are grateful to the Ministry of Research, Technology and Higher Education of the Republic of Indonesia, Research and Community Service Brawijaya University and Saiful Anwar Hospital for their support and assistance.

Key words: Symptoms characteristic; chest pain; acute coronary syndrome; diabetes mellitus.

Contributions: All authors contributed equally to this article. HM, YOS, SA carried out the study, while ML served as a supervisor and reviewed the final article; MSR kindly and thoughtfully managed this study.

Conflict of interest: The authors declare no conflict of interest.

Funding: This work was supported by the Ministry of Research, Technology and Higher Education of the Republic of Indonesia and Brawijaya University.

Ethical Approval: This study was approved by the Ethics Committee of dr. Saiful Anwar Malang Hospital, Malang, Indonesia.

Conference presentation: Part of this study was presented at the $1^{\text {st }}$ International Nursing and Health Sciences Symposium, November $13^{\text {th }}$ to $15^{\text {th }} 2020$, Brawijaya University, Malang, Indonesia.

Received for publication: 14 January 2021.

Accepted for publication: 15 March 2021.

o Copyright: the Author(s), 2021

Licensee PAGEPress, Italy

Journal of Public Health Research 2021;10:2186

doi:10.4081/jphr.2021.2186

This work is licensed under a Creative Commons Attribution NonCommercial 4.0 License (CC BY-NC 4.0).

\section{References}

1. WHO. About cardiovascular diseases. Geneva: World Health Organization; 2015. Available from: https://www.who.int/cardiovascular_diseases/about_cvd/en/

2. Dharma S, Andriantoro H, Dakota I, et al. Organisation of reperfusion therapy for STEMI in a developing country. BMJ Openheart 2015;2:1-7.

3. Price SA, Wilson LM. [Pathophysiology. Clinical concepts of disease processes].[Translation in Indonesian]. Jakarta: EGC; 2005.

4. Herlitz J, Wireklintsundstrom B, Bang A, et al. Early identification and delay to treatment in myocardial infarction and stroke: differences and similarities. Scand J Trauma Resusc Emerg Med 2010;18:48.

5. Malik MA, Alam Khan S, Safdar S, et al. Chest pain as a presenting complaint in patients with acute myocardial infarction (AMI). Pak J Med Sci 2013;29:565-8.

6. Rosamond W, Flegal K, Friday G, et al. Heart disease and stroke statistics--2007 update: a report from the American Heart Association Statistics Committee and Stroke Statistics Subcommittee. Circulation 2007;115:e69-171. 
7. DeVon HA, Ryan CJ, Rankin SH, et al. Classifying subgroups of patients with symptoms of acute coronary syndromes: A cluster analysis. Res Nurs Health 2010;33:386-97.

8. Blendea MC, McFarlane SI, Isenovic ER, et al. Heart disease in diabetic patients. Curr Diab Rep 20103;3:223-9.

9. Brieger D, Eagle KA, Goodman SG, et al. Acute coronary syndromes without chest pain, an underdiagnosed and undertreated high-risk group: insights from the Global Registry of Acute Coronary Events. Chest 2004;126:461-9.

10. Kannel WB, Castelli WP, Gordon T. Cholesterol in the prediction of atherosclerotic disease. New perspectives based on the Framingham study. Ann Intern Med 1979;90:85-91.

11. Manzella D, Paolisso G. Cardiac autonomic activity and Type II diabetes mellitus. Clin Sci (Lond) 2005;108:93-9.

12. De Bacquer D, De Backer G. Predictive ability of the SCORE Belgium risk chart for cardiovascular mortality. Int J Cardiol 2010;143:385-90.

13. Malik MA, Alam Khan S, Safdar S, et al. Chest Pain as a presenting complaint in patients with acute myocardial infarction (AMI). Pak J Med Sci 2013;29:565-8.

14. DeVon HA, Rosenfeld A, Steffen AD, et al. Sensitivity, specificity, and sex differences in symptoms reported on the 13-item acute coronary syndrome checklist. J Am Heart Assoc 2014;3:e000586.

15. Funk M, Naum JB, Milner KA, et al. Presentation and symptom predictors of coronary heart disease in patients with and without diabetes. Am J Emerg Med 2001;19:482-7.

16. PERKI. [Pedoman Tatalaksana Hipertensi pada Penyakit Kardiovaskular (Guidelines for the management of hypertension in cardiovascular disease)].[Book in Indonesian]. Jakarta:
PERKI; 2018.

17. Thuresson M, Jarlöv MB, Lindahl B, et al. Symptoms and type of symptom onset in acute coronary syndrome in relation to ST elevation, sex, age, and a history of diabetes. Am Heart J 2005;150:234-42.

18. DeVon HA, Penckofer SM, Zerwic JJ. Symptoms of unstable angina in patients with and without diabetes. Res Nurs Health 2005;28:136-43.

19. Albarran J, Durham B, Gowers J, et al. Is the radiation of chest pain a useful indicator of myocardial infarction? A prospective study of 541 patients. Accid Emerg Nurs 2002;10:2-9.

20. DeVon HA, Penckofer S, Larimer K. The Association of diabetes and older age with the absence of chest pain during acute coronary syndromes. West J Nurs Res 2007;30:130-44.

21. Canto JG, Shlipak MG, Rogers WJ, et al. Prevalence, clinical characteristics, and mortality among patients with myocardial infarction presenting without chest pain. JAMA 2000;283:3223-9.

22. Junghans C, Sekhri N, Zaman MJ, et al. Atypical chest pain in diabetic patients with suspected stable angina: impact on diagnosis and coronary outcomes. Eur Heart J Qual Care Clin Outcomes 2015;1:37-43.

23. Ruiz-García J, Lerman A, Weisz G, et al. Age- and genderrelated changes in plaque composition in patients with acute coronary syndrome: the PROSPECT study. EuroIntervention 2012;8:929-38.

24. Bruyninckx R, Aertgeerts B, Bruyninckx P, et al. Signs and symptoms in diagnosing acute myocardial infarction and acute coronary syndrome: a diagnostic meta-analysis. Br J Gen Pract 2008;58:105-11. 